\title{
3 Student wellbeing interventions and implementation
}

\author{
Dianne A. Vella-Brodrick and Tan-Chyuan Chin
}

\section{How to use this policy}

Positive Psychology, which promotes feeling good, functioning well and doing good, is gaining traction in education settings. Wellbeing is recognised as being important in its own right and as a prerequisite for learning. With growing pressure on schools to embed wellbeing content in an already busy curriculum, many schools draw from external interventions, talks and one-off student wellbeing experiences. Many of these practices do not have sufficient support from research to justify and support their expense or the time taken to invest in them. The purpose of this policy is to discuss the importance of implementing and embedding interventions that are empirically robust. To ensure their sustained practice and benefits, programs also need to have sufficient scope and sequence within the school's existing program and relevance for the school community.

Selecting quality wellbeing interventions for students can be a daunting task for schools. This policy is intended to guide educational leaders and school communities to develop a clear process for including student wellbeing interventions at their schools. It will elucidate some of the critical factors that are associated with the most successful wellbeing interventions. Hence, it serves as a useful compass for schools seeking to implement wellbeing interventions and to optimise the positive effects for students of these interventions.

This policy example is intentionally broad and school policy creators are encouraged to delete and build upon suggestions below to create a policy that best represents their school.

[To adapt and use this policy, delete or modify the text as indicated]

\section{[INSERT name of school] Student wellbeing interventions and implementation}

\section{Rationale}

Wellbeing interventions seek to improve the mental health of individuals or groups using strengths-based strategies focused on building positive emotions, 
engagement, quality relationships, meaning and feelings of accomplishment as reflected in Seligman's (2011) Positive Emotions, Engagement, Relationships, Meaning, and Accomplishment (PERMA) model. The development and uptake of wellbeing interventions in school settings is escalating (Green et al., 2014; Slemp et al., 2017). This is in part due to the growing recognition that schools have an important role to play in helping to promote student wellbeing. Wellbeing interventions have the potential to curb mental ill health and to impart useful wellbeing skills that can lead to enhanced wellbeing (Sin \& Lyubomirsky, 2009). School-based wellbeing interventions have also been found to be beneficial, particularly when they integrate positive psychology interventions (Cilar et al., 2020).

A universal approach to wellbeing in a school context means that most young people will have access to the wellbeing intervention irrespective of their mental health status. Widespread implementation will contribute to a common language and understanding of wellbeing, help promote equity and erode the social stigma often associated with seeking help from mental health professionals (Gray \& Daraganova, 2017; Rickwood et al., 2005). While this is a positive step in helping to address the mental health crisis experienced by many young people (Carlisle et al., 2019; Vos et al., 2015) and to promote optimal states of functioning and flourishing, those who are responsible for selecting student wellbeing interventions can feel overwhelmed with the vast number of choices available. Many questions arise and it can be difficult to select the "right" wellbeing initiative. For example, what content or program should be included and for what student Year levels? What is the ideal length of time to run the initiative? What evidence is there that this is a good program? How will we know if the program is working for our students?

It is imperative that any intervention associated with the mental health and wellbeing of young people has a strong evidence base of relevant benefits. Although positive interventions generally focus on promoting wellbeing and are considered to be engaging, we cannot underestimate the possibility of harm with any mental health intervention and thus responsible steps need to be taken in the selection, resourcing, monitoring and evaluation phases.

\section{Purpose}

The purpose of this policy is to help guide school communities in selecting and delivering student wellbeing interventions that are both effective for and relevant to achieving the desired wellbeing outcomes.

\section{Scope}

The policy is relevant to school communities who are involved in the selection of student wellbeing initiatives. This can include teachers wanting to integrate wellbeing education in some of their classes, School Leaders who would like to roll out an intervention for a cohort of students or wellbeing, pastoral care 


\section{0}

Vella-Brodrick \& Chin

and leadership staff who would like to adopt a whole-school approach to wellbeing education.

Educational groups such as Departments of Education or School Networks may also have an interest in adopting wellbeing interventions for multiple schools. This policy would be equally relevant to these groups and takes on critical importance when project findings of intervention efficacy are intended to inform the practices adopted in other schools.

There should be a dedicated team - with a clear leader who has relevant experience in student wellbeing - that oversees the program selection and delivery, including the ethical requirements, monitoring and communication of program effects.

[INSERT specific roles and responsibilities of individuals or teams]

\section{Policy statement}

\section{Foundational principles and governance}

[INSERT name of school] will adopt a strategic approach for implementing wellbeing interventions that is consistent with implementation science, ethics and best practice principles (Glasgow, Harden, Gaglio, Rabin, Smith, Porter, Ory \& Estabrooks, 2019; King et al., 2020; Kwan, McGinnes, Estabrooks, Waxmonsky \& Glasgow, 2019). A strategic approach provides a clear process for change and is useful for identifying anticipated outcomes (Stein \& Valters, 2012).

[INSERT name of school] will adopt a comprehensive systems approach to wellbeing interventions. Wellbeing interventions sit within a complex system and hence, they are likely to work best using a whole-school approach that aligns with and supports the intervention (Hoare, Bott \& Robinson, 2017; Waters, 2011).

This includes:

1 Creating opportunities within all school life to practice and discuss the usefulness of the wellbeing intervention.

2 Modelling key components of the wellbeing intervention by school staff.

3 Ensuring the application of the wellbeing intervention is visible to students and the school community through policy, day-to-day communications and behaviour.

4 Fostering collaborations between wellbeing staff such as school counsellors and psychologists, the pastoral care team and health education teachers, as well as with community health services.

[INSERT name of school] will develop a plan that is endorsed and fully supported by school leadership and school parent committees (Hoare, Bott \& Robinson, 2017; Waters, 2011).

[INSERT name of school] will consult with experts in the field (such as other schools with extensive wellbeing experience, child and youth service groups, and university scholars well versed in the application of wellbeing 
science) to receive advice on the wellbeing intervention plan. This supports the importance of the science-practitioner relationship and ecological validity (Soutter, O’Steen \& Gilmore, 2014).

[INSERT name of school] will demonstrate a high level of "readiness" prior to implementing the intervention, such that school staff will be sufficiently motivated and prepared to implement the student wellbeing program (Hoare, Bott \& Robinson, 2017; Waters, 2011).

\section{Student contribution, engagement and access}

[INSERT name of school] recognises that wellbeing education needs to be meaningful and relevant to students' needs (Vella-Brodrick, Chin, \& Rickard, 2019; Vella-Brodrick, Rickard, \& Chin, 2017). Hence, we will consult with students to better understand what their wellbeing needs are.

[INSERT name of school] will provide students with a safe and confidential forum to voice their experiences, challenges and concerns (Powell, Graham, Fitzgerald, Thomas \& White, 2018).

Students will be given the opportunity to contribute to the planning, design and implementation of wellbeing initiatives at [INSERT name of school]. The school can facilitate the co-design by using a range of age-appropriate methods, such as focus groups, interviews and self-report surveys to incorporate students' perspectives and expectations (Blomkamp, 2018). This transforms the students' participation from receiving education and information, to being involved through active engagement and consultation, and ideally being part of the decision-making process by co-designing and co-producing the activities to share and balance the power and participation between staff and students (Slay \& Stephens, 2013).

[INSERT name of school] will involve young people in the decision-making process associated with wellbeing programs that concern them. Their views should be considered particularly as age and maturity increases (Lansdown, Jimerson \& Shahroozi 2014).

[INSERT name of school] will provide equitable opportunities for all students to contribute to and participate in student wellbeing interventions. This will help to make programs relevant to diverse groups (Lansdown et al., 2014).

[INSERT name of school] will provide wellbeing interventions that are accessible, relevant and responsive to the contextual and cultural needs of our students. The social-ecological model suggests that optimal change and outcomes are facilitated by interventions that consider and address the interrelatedness of individual, familial, inter/intrapersonal and community contexts (Bronfenbrenner, 1994).

[INSERT name of school] will implement evidence-based wellbeing interventions but will adapt these where necessary to suit the specific school context (Street, 2017). 


\section{Adequate support and training for staff and students}

[INSERT name of school] will provide staff with professional development opportunities and adequate time release to acquire knowledge and build capacity to achieve optimal outcomes for all members of the learning community (Chin, Stevenson, Jacques-Hamilton, \& Vella-Brodrick, 2019; Soutter, O’Steen \& Gilmore, 2014).

[INSERT name of school] will ascertain the level of resources needed and available to support the intervention. We will also source additional resources needed to successfully deliver the program. Building internal capacity supports a whole of school approach and enables sustained practice (Desimone, 2002).

[INSERT name of school] will ensure professional support services are available to students to protect them and to enable their rights (Lansdown et al., 2014).

\section{Allocate adequate resources to assess wellbeing needs, effects and impact}

[INSERT name of school] will routinely conduct a wellbeing needs analysis to guide the selection of relevant interventions. The intervention needs to meet current needs and valued outcomes. This will promote student buy-in, which can contribute to students' engagement in active learning (Cavanagh et al., 2016).

[INSERT name of school] will measure and monitor the wellbeing of students using reliable quantitative and qualitative methods on a regular basis (e.g., annually), including at baseline, to examine if there are shifts in wellbeing in response to the intervention. Measurement needs to be built into any wellbeing strategy as this will help to determine how well the program is working to achieve the intended outcomes (Glasgow et al., 2019; Seligman, 2013).

[INSERT name of school] will acquire relevant expertise to accurately analyse and interpret data collected via standardised measures or specialised tools. This is consistent with the recommendation to optimise both internal and external resources (Zhang, 2016).

[INSERT name of school] will monitor and document the implementation process to ensure the program is being delivered as intended (Glasgow et al., 2019).

[INSERT name of school] will collect feedback about the intervention experience, from those delivering the program, program recipients and significant others such as parents. This will enable the intervention to be improved for future delivery and increase the likelihood the intervention will be maintained (Noell \& Gansle, 2009). 


\section{Rating of evidence base}

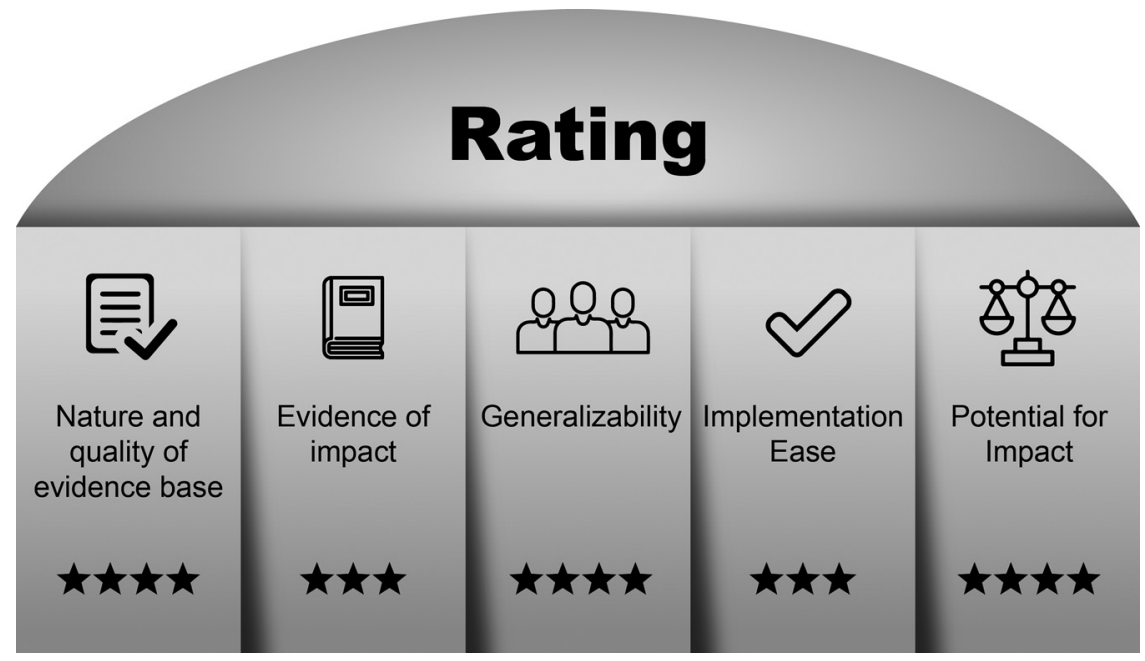

Figure 3.1. Student Wellbeing Interventions and Implementation Rating of Evidence.

Author note. There are a number of well-established design and implementation frameworks that have been well-supported. While there is some short-term evidence, more information about longer-term impact is needed. Given the whole-school and systems approach, an investment in relevant resources is needed for improved success.

\section{Authorship}

Professor Dianne A. Vella-Brodrick, Centre for Positive Psychology, Melbourne Graduate School of Education, University of Melbourne

Dr Tan-Chyuan Chin, Centre for Positive Psychology, Melbourne Graduate School of Education, University of Melbourne

[INSERT RELEVANT STAFF MEMBERS]

\section{Related policy and documents}

[INSERT RELEVANT POLICY AND DOCUMENTS]

\section{Date of ratification}

This policy was ratified on the [INSERT DATE].

\section{Date of review}

This policy will be reviewed by [INSERT DATE]. 


\section{Further reading}

Nilsen, P. (2015). Making sense of implementation theories, models and frameworks. Implementation Science, 10(53).

\section{References}

Blomkamp, E. (2018). The promise of co-design for public policy. Australian Journal of Public Administration, 77, 729-743.

Bronfenbrenner, U. (1994). Ecological models of human development. In T. Husen \& T. N. Postlethwaite (Eds.), International Encyclopedia of education 2nd ed., Vol. 3, (pp. 1643-1647). Oxford: Pergamon Press.

Carlisle, E., Fildes, J., Hall, S., Perrens, B., Perdriau, A., \& Plummer, J. (2019). Youth survey report. Sydney, NSW: Mission Australia.

Cavanagh, A. J., Aragón, O. R., Chen, X., Couch, A., Durham, F., Bobrownicki, A., Hanauer, D. I., \& Graham, M. J. (2016). Student buy-in to active learning in a college science course. CBE Life Sciences Education, 15(4), ar76.

Chin, T-C., Stevenson, I., Jacques-Hamilton, R., \& Vella-Brodrick, D. A. (2019). Wellbeing in the Maroondah Network of Schools: Understanding the wellbeing needs of students, staff, parents and carers in Maroondah. Commissioned by The Department of Education and Training, Victoria. Parkville: The University of Melbourne.

Cilar, L., Štiglic, G., Kmetec, S., Barr, O., \& Pajnkihar, M. (2020). Effectiveness of school-based mental well-being interventions among adolescents: A systematic review. Journal of Advanced Nursing, 76, 2023-2045.

Desimone, L. (2002). How can comprehensive school reform models be successfully implemented? Review of Educational Research, 72(3), 433-479.

Gray, S., \& Daraganova, G. (2017). Adolescent help-seeking. Melbourne: Australian Institute of Family Studies.

Glasgow, R. E., Harden, S. M., Gaglio, B., Rabin, B., Smith, M. L., Porter, G. C., Ory, M. G., \& Estabrooks, P. A. (2019). RE-AIM planning and evaluation framework: Adapting to new science and practice with a 20 -year review. Frontiers in Public Health, 7(64).

Green, C. P., Navarro-Paniagua, M., Ximénez-de-Embún, D. P., \& Mancebón, M-J. (2014). School choice and student wellbeing. Economics of Education Review, 38, $139-150$.

Hoare, E., Bott, D., \& Robinson, J. (2017). Learn it, live it, teach it, embed it: Implementing a whole school approach to foster positive mental health and well-being through positive education. International Journal of Wellbeing, 7(3), $56-70$.

King, D. K., Shoup, J. A., Raebel, M. A., Anderson, C. B., Wagner, N. M., Ritzwoller, D. P., \& Bender, B. G. (2020). Planning for implementation success using RE-AIM and CFIR frameworks: A qualitative study. Frontiers in Public Health, $8(59)$.

Kwan, B. M., McGinnes, H. L., Ory, M. G., Estabrooks, P. A., Waxmonsky, J. A., \& Glasgow, R. E. (2019). RE-AIM in the real world: Use of the RE-AIM framework for program planning and evaluation in clinical and community settings. Frontiers in Public Health, 7(345). 
Lansdown, G., Jimerson, S. R., \& Shahroozi, R. (2014). Children's rights and school psychology: Children's right to participation. Journal of School Psychology, 52(1), 3-12.

Noell, G. H., \& Gansle, K. A. (2009). Moving from good ideas in educational systems change to sustainable program implementation: Coming to terms with some of the realities. Psychology in the Schools, 46(1), 78-88.

Powell, M. A., Graham, A., Fitzgerald, R., Thomas, N., \& White, N. E. (2018). Wellbeing in schools: What do students tell us? The Australian Educational Researcher, 45, 515-531.

Rickwood, D., Deane, F. P., Wilson, C. J., \& Ciarrochi, J. (2005). Young people's helpseeking for mental health problems. Australian E-Journal for the Advancement of Mental Health, 4, 218-251.

Seligman, M. (2011). Building the state of well-being: A strategy for South Australia (Adelaide Thinker in Residence 2012-2013). South Australia: Government of South Australia.

Sin, N. L., \& Lyubomirsky, S. (2009). Enhancing well-being and alleviating depressive symptoms with positive psychology interventions: A practice-friendly meta-analysis. Journal of Clinical Psychology, 65, 467-487.

Slay, J. \& Stephens, L. (2013). Co-production in mental health: A literature review. London: New Economics Foundation.

Slemp, G. R., Chin, T-C., Kern, M. L., Siokou, C., Loton, D., Oades, L. G., VellaBrodrick, D., Waters, L. (2017). Positive education in Australia: Practice, measurement, and future directions. Social and Emotional Learning in Australia and the Asia-Pacific, 2017, 101-122.

Soutter, A. K., O’Steen, B., \& Gilmore, A. (2014). The student well-being model: A conceptual framework for the development of student wellbeing indicators. International Journal of Adolescence and Youth, 19(4), 496-520.

Stein, D., \& Valters, C. (2012). Understanding theory of change in international development: A review of existing knowledge (JSRP Paper 1). London: JSRP and The Asia Foundation.

Street, H. (2017). Measures of success: Exploring the importance of context in the delivery of wellbeing and social and emotional learning programmes in Australian primary and secondary schools. In E. Frydenberg, A. Martin, \& R. Collie (Eds.), Social and emotional learning in Australia and the Asia-Pacific. (1st ed., pp. 83-99). Springer.

Vos, T., Barber, R. M., Bell, B., Bertozzi-Villa, A., Biryukov, S., Colliger, I., ... Murray, C. J. L. (2015). Global, regional and national incidence, prevalence and years lived with disability for 301 acute and chronic diseases and injuries in 188 countries, 1990-2013: A systematic analysis for the Global Burden of Disease Study 2013. The Lancet, 386 (9995), 743-800.

Vella-Brodrick, D. A., Chin, T-C., Rickard, N. S. (2019). Examining the processes and effects of an exemplar school-based well-being approach on student competency, autonomy and relatedness. Health Promotion International, daz115.

Vella-Brodrick, D. A., Rickard, N. S., \& Chin, T-C. (2017). Evaluating positive education: A framework and case study. In N. J. L. Brown, T. Lomas, \& F. J. Eiroa-Orosa (Eds.), The Routledge international handbook of critical positive psychology (pp. 488-502). London: Routledge.

Waters, L. (2011). A review of school-based positive psychology interventions. The Australian Educational and Developmental Psychologist, 28(2), 75-90.

Zhang, Y. (2016). Making students happy with wellbeing-oriented education: Case study of a secondary school in China. Asia-Pacific Education Researcher, 25, 463-471. 